\title{
Applying Fuzzy Analytic Hierarchy Process (FAHP) $\alpha$-Cut Based and TOPSIS Methods to Determine Bali Provincial Road Handling Priority
}

\author{
Wedagama, D.M.P. ${ }^{1}$ and Frederika, A. ${ }^{1}$
}

\begin{abstract}
The Analytic Hierarchy Process (AHP) method has been employed in a previous study to determine Bali provincial road handling priority. This method usually overlooks the decision maker's degrees of confidence and optimism of the decision. Meanwhile, Fuzzy Analytic Hierarchy Process (FAHP) $\alpha$-cut based and Technique for Order Preference by Similarity to Ideal Solution (TOPSIS) methods allow the researcher to estimate the overall road handling priority considering on degrees of confidence and optimism of the decision. The present study aims at determining Bali provincial road handling priority using FAHP $\alpha$-cut based and TOPSIS methods. The current study shows that decision makers' degree of confidence in both pessimistic and moderate situations and optimism from certain to the most uncertain conditions suggesting the same road link as the highest priority compared to the previous study. Both current and previous studies also conclude the same road link as the lowest road handling priority.
\end{abstract}

Keywords: Road handling, fuzzy AHP $\alpha$-cut based method, TOPSIS.

\section{Introduction}

Road handling priority is deemed as a complicated multi-criteria decision making process. In so doing, various aspects including economics, relations among regions, accessibility, political considerations, defence, and security should be considered. In a previous study [1], the macro transportation system [2] was used to construct the main and sub criteria of the problem and the Analytic Hierarchy Process (AHP) was used to determine provincial road handling in Bali. The study suggested that the AHP is effective and logical in determining Bali provincial road handling priority.

The AHP method, however, may not entirely show a way of human thinking because the experts/decision makers typically tend to express interval judgments rather than sorts of single numeric values [3]. In addition, the AHP can not be entirely put into practice as it is usually overlooking the decision maker's degree of confidence and degree of optimism of the decision. The pairwise comparison (PC) ratios in the AHP are in crisp real numbers [4] and decisions always consisting vagueness and variety of meaning. The descriptions of decision makers are typically linguistic and vague.

${ }^{1}$ Department of Civil Engineering, Faculty of Engineering Udayana University, Bukit Jimbaran-Bali, INDONESIA.

Email: priyantha_wedagama@googlemail.com

Note: Discussion is expected before November, $1^{\text {st }} 2011$, and will be published in the "Civil Engineering Dimension" volume 14, number 1, March 2012.

Received 11 March 2011; revised 15 August 2011; accepted 19 August 2011.
Fuzziness and vagueness are typical in many decision-making problems, so that fuzzy sets could be combined with the PC [3,5]. Fuzzy AHP (FAHP) therefore, is qualified in describing a human's judgement of vagueness when complex multiattribute decision making problems are considered $[5,6]$.

In this study, fuzzy numbers are used to score judgments of evaluation criteria. In so doing, a crisp judgement matrix is incorporated with the index of optimism to deal with criteria weighting. More specifically, defuzzification is carried out by performing the interval performance matrix with $\alpha$-cut and the optimism index, $\beta$. This is called FAHP $\alpha$-cut based method. Meanwhile, Technique for Order Preference by Similarity to Ideal Solution (TOPSIS) is a relevant method to determine the best alternative using the positive and negative ideal solutions [7]. The positive ideal solution is made of all best values of reasonable criteria, while negative ideal solution containing all worst values of realistic criteria [6].

This study aims to determine provincial road handling priority using FAHP $\alpha$-cut based and TOPSIS methods considering Bali provincial road links as the case study area. The same set of data used in the previous study [1] is employed in this study. FAHP $\alpha$-cut based method is used to determine the weights of the criteria by experts and then TOPSIS method is used to determine road links handling priority. Further, changes of ideal solution under different risk environments are also simulated. 


\section{FAHP and TOPSIS}

\section{Fuzzy Numbers}

Fuzzy quantities are specifically represented with fuzzy numbers with interval between 0 and 1 . A fuzzy quantity, $\mathrm{M}(\mathrm{x})$, is used to measure the proximity of $\mathrm{M}(\mathrm{x})$ predicting a real number $\mathrm{r}$. In so doing, Triangular fuzzy numbers (TFNs) are easy and practical to use in a fuzzy environment. A triangular fuzzy number, $\tilde{M}$ is shown in Figure 1 [7].

The TFNs in a fuzzy event have three parameters: 1, $\mathrm{m}$, and $\mathrm{u}$, indicating the smallest, the most promising, and the largest possible values respectively. Their membership functions are defined as follows:

$$
\mu(\mathrm{x} / \tilde{M})= \begin{cases}0, & \mathrm{x}<\mathrm{l}, \\ (\mathrm{x}-\mathrm{l}) /(\mathrm{m}-\mathrm{l}), & \mathrm{l} \leq \mathrm{x} \leq \mathrm{m} \\ (\mathrm{u}-\mathrm{x}) /(\mathrm{u}-\mathrm{m}), & \mathrm{m} \leq \mathrm{x} \leq \mathrm{u} \\ 0, & \mathrm{x}>\mathrm{u}\end{cases}
$$

As the confidence interval level is expressed with $\alpha$, TFN is defined as:

$$
\begin{gathered}
\forall \alpha \in[0,1] \text { and } \tilde{M}_{\alpha}=\left[1^{\alpha}, \mathrm{u}^{\alpha}\right]=[(\mathrm{m}-\mathrm{l}) \alpha+\alpha,-(\mathrm{u}-\mathrm{m}) \\
\alpha+\mathrm{u}]
\end{gathered}
$$

Some positive fuzzy numbers main operations expressed with the confidence interval are:

$$
\begin{aligned}
& \forall m_{L}, m_{R}, n_{L}, n_{R} \in R^{+}, \tilde{M}_{\alpha}=\left[m_{L}^{\alpha}, m_{R}^{\alpha}\right], \\
& \tilde{N}_{\alpha}=\left[n_{L}^{\alpha}, n_{R}^{\alpha}\right], \alpha \in[0,1] \\
& \tilde{M} \oplus \tilde{N}=\left[m_{L}^{\alpha}+n_{L}^{\alpha}, m_{R}^{\alpha}+n_{R}^{\alpha}\right] \\
& \tilde{M} \Theta \tilde{N}=\left[m_{L}^{\alpha}-n_{L}^{\alpha}, m_{R}^{\alpha}-n_{R}^{\alpha}\right] \\
& \tilde{M} \otimes \tilde{N}=\left[m_{L}^{\alpha} n_{L}^{\alpha}, m_{R}^{\alpha} n_{R}^{\alpha}\right] \\
& \tilde{M} \div \tilde{N}=\left[m_{L}^{\alpha} / n_{L}^{\alpha}, m_{R}^{\alpha} / n_{R}^{\alpha}\right]
\end{aligned}
$$

The TFN, $\tilde{1}$ to $\tilde{9}$, are used to enhance the conventional Saaty's nine-point scaling scheme [4]. All elements in the judgement matrix and weight vectors are represented by TFN numbers and ratio scales as shown in Tables 1 and 2 respectively.

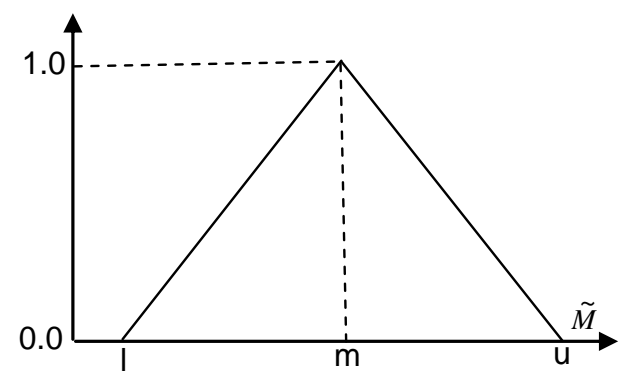

Figure 1. A Triangular Fuzzy Number, $\tilde{M}$
Table 1. Fuzzy Number, Membership function and Linguistic Term

\begin{tabular}{ccc}
\hline Fuzzy Number & Membership function & Linguistic Term \\
\hline$\tilde{1}$ & $(1,1,3)$ & Very Poor \\
$\tilde{3}$ & $(1,3,5)$ & Poor \\
$\tilde{5}$ & $(3,5,7)$ & Ordinary \\
$\tilde{7}$ & $(5,7,9)$ & Excellent \\
$\tilde{9}$ & $(7,9,9)$ & Very Excellent \\
\hline
\end{tabular}

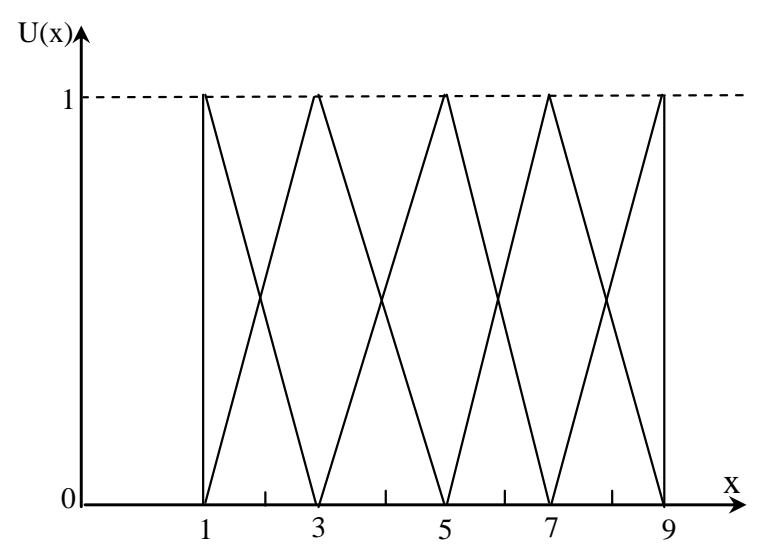

Figure 2. Triangular Fuzzy Ratio Scales

\section{FAHP}

A fuzzy ratio scale exactly corresponds to a sub score, $\widetilde{G}_{i j k}$, representing the sub-score of alternative, $\mathrm{A}_{\mathrm{i}}$, with respect to sub-criterion, $\mathrm{C}_{\mathrm{jk}}$. After obtaining all $\tilde{G}_{i j k}$ of $\mathrm{A}_{\mathrm{i}}$ with respect to all $\mathrm{C}_{\mathrm{jk}}$, the judgement score, $\tilde{a}_{i j}$, is computed. Equation 4 is used to separately aggregate all $\mathrm{A}_{\mathrm{i}}$, with respect to $\mathrm{C}_{\mathrm{jk}}$, which belong to the same criterion, $\mathrm{C}_{\mathrm{j}}$.

$$
\tilde{G}_{i j k}=\sum_{k=1}^{q} \tilde{G}_{i j k}, \mathrm{i}=1,2, \ldots \mathrm{n} \quad \mathrm{j}=1,2, \ldots \mathrm{m} \quad \mathrm{k}=1,2, . . \mathrm{q}
$$

All scores from Equation 1 are calculated to form a decision matrix. A normalisation process is conducted to allow a matching process with the weight vector. Each criterion, $\mathrm{C}_{\mathrm{j}}$, in a decision matrix is normalised by using Equation 5. A fuzzy judgement matrix, A, is obtained after normalising.

$$
\tilde{a}_{i j}=\frac{\tilde{G}_{i j}}{\sqrt{\sum_{i=1}^{n}\left(\tilde{G}_{i j}\right)^{2}}}, \mathrm{j}=1,2, \ldots . \mathrm{m}
$$

The A matrix is multiplied with the corresponding fuzzy weight vector to obtain the fuzzy performance matrix, H. This represents the overall fuzzy performance which each alternative corresponds to all criteria. Meanwhile, the weight vector represents the relative importance among each criterion is calculated with AHP PC or with immediate expert's judgement. 
The different experts may define the different weight vectors because they usually give the imprecise evaluation during the decision process. To handle this, a group of decisions on AHP with TFN are used to improve the original PC. A comprehensive PC matrix, $\mathrm{D}$ is constructed by integrating all decision makers' grades, $b_{\text {jep }}$, through Equations 6 to 10 . A score $b_{\text {jep }}$ represents a decision maker $\mathrm{D}_{\mathrm{p}}$, measures of the relative importance by using Saaty's scale 1-9 between each criteria.

$\mathrm{L}_{\mathrm{je}}=\min \left(b_{\mathrm{jep}}\right), \mathrm{p}=1,2, \ldots \mathrm{t} \quad \mathrm{j}=1,2 \ldots \mathrm{m} \quad \mathrm{e}=1,2 \ldots \mathrm{m}$

$\mathrm{M}_{\mathrm{je}}=\frac{\sum_{p=1}^{t} b_{j e p}}{p}, \mathrm{p}=1,2, \ldots \mathrm{t} \quad \mathrm{j}=1,2 \ldots \mathrm{m} \quad \mathrm{e}=1,2 \ldots \mathrm{m}$

$\mathrm{U}_{\mathrm{je}}=\max \left(U_{\text {jep }}\right), \mathrm{p}=1,2, \ldots \mathrm{t} \quad \mathrm{j}=1,2 \ldots \mathrm{m} \quad \mathrm{e}=1,2 \ldots \mathrm{m}$

$\tilde{b}_{j e}=\left(\mathrm{L}_{\mathrm{je}}, \mathrm{M}_{\mathrm{je}}, \mathrm{U}_{\mathrm{je}}\right), \quad \mathrm{j}=1,2 \ldots \mathrm{m} \quad \mathrm{e}=1,2 \ldots \mathrm{m}$

A comprehensive score, $\widetilde{b}_{j e}$, represents the relative importance among each criterion with TFN. In order to acquire a weight, $\tilde{w}_{j}$, which corresponds to a specific criterion, $\mathrm{C}_{\mathrm{j}}$, the relative weights between all criteria is calculated as follows:

$$
\tilde{w}_{j}=\frac{\sum_{e=1}^{m} \tilde{b}_{j e}}{\sum_{j=1}^{m} \sum_{e=1}^{m} \tilde{b}_{j e}}, \mathrm{j}=1,2 \ldots \mathrm{m} \mathrm{e}=1,2 \ldots . \mathrm{m}
$$

The criteria weights collectively make up a fuzzy weight vector, $\mathrm{W}$, as in Equation 11.

$\mathrm{W}=\left(\tilde{w}_{1}, \tilde{w}_{2}, \ldots \ldots \ldots . . \tilde{w}_{m}\right)$

The experts' subjective judgement produces uncertain and imprecise relations between criteria and alternatives and is usually accompanied with some unclear factors including the decision maker's degree of confidence and degree of optimism of decision making. To overcome this situation, defuzzification is carried out by performing the interval performance matrix with $\alpha$-cut and the optimism index, $\beta$. The interval performance matrix, $\mathrm{H}_{\alpha}$, is computed by using $\alpha$-cut method on the $\mathrm{H}$ matrix. Each fuzzy performance score, $\tilde{h}_{i j}$, is joined to respectively form an interval $\left[\tilde{h}_{i j l}^{\alpha}, \tilde{h}_{i j r}^{\alpha}\right]$ as shown in Figure 3.

$$
\begin{gathered}
\tilde{h}_{i j l}^{\alpha}=\mathrm{L}_{\mathrm{ij}}+\alpha\left(\mathrm{M}_{\mathrm{ij}}-\mathrm{L}_{\mathrm{ij}}\right) \\
\tilde{h}_{i j r}^{\alpha}=\mathrm{U}_{\mathrm{ij}}+\alpha\left(\mathrm{U}_{\mathrm{ij}}-\mathrm{M}_{\mathrm{ij}}\right)
\end{gathered}
$$

In Figure 3, the $\tilde{h}_{i j l}^{\alpha}$ and $\tilde{h}_{i j r}^{\alpha}$ respectively represent the left point and right point of the range of the triangle after using $\alpha$-cut. The range of $\alpha$ is between 0 and 1 . If the decision makers establish the higher degree of confidence, $\alpha$, it shows they have asked sufficient information to support their decisions. Therefore, the higher degree of confidence is corresponding to the lower uncertainty.

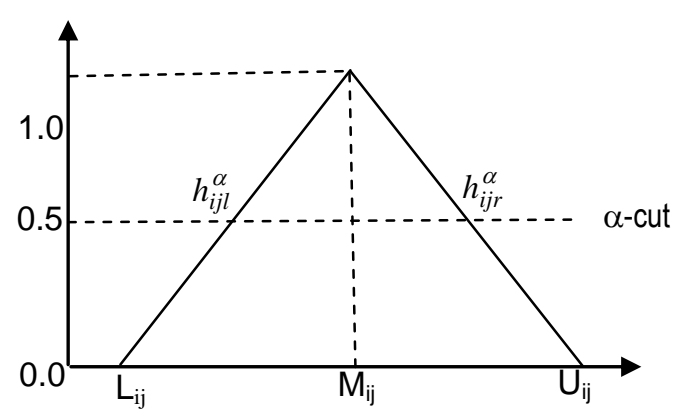

Figure 3. Range of Triangle using $\alpha$-cut

The degree of optimism includes the decision makers' attitude that may be: optimistic, moderate, or pessimistic. The optimism index is also applied to be a defuzzifier. Defuzzification is conducted by joining the optimism index to produce the final crisp numbers. The overall crisp performance matrix, $H_{\beta}^{\alpha}$ is calculated as follows [3]:

$h_{i j \beta}^{\alpha}=\beta h_{i j l}^{\alpha}+(1-\beta) h_{i j r}^{\alpha}, \quad 0 \leq \alpha \leq 1 \quad 0 \leq \beta \leq 1$

The $h_{i j \beta}^{\alpha}$ indicates the crisp performance score which each alternative, Ai, corresponds to all criteria, $\mathrm{C}_{j}$ under $\alpha$ and $\beta$.

\section{TOPSIS}

Technique for Order Preference by Similarity to Ideal Solution (TOPSIS) defines two kinds of solutions including the positive and negative ideal solutions. The positive ideal solution is the maximal benefits solution, and containing all best values of criteria. On the other hand, the negative ideal solution is the minimal benefits solution and composed of the all worst values of criteria. TOPSIS defines solutions as the points which are nearest to the positive ideal point and farthest from the negative ideal solution at the same time. The positive ideal solution, $h_{i j \beta}^{\alpha+}$, and the negative ideal solution, $h_{i j \beta}^{\alpha-}$, is determined as follows [7]:

$h_{j \beta}^{\alpha+}=\left\{\left(\max h_{i j \beta}^{\alpha} \mid j \in J\right),\left(\min h_{i j \beta}^{\alpha} \mid j \in J^{\prime}\right), i=1,2, \ldots . n\right)$

$h_{j \beta}^{\alpha-}=\left\{\left(\min h_{i j \beta}^{\alpha} \mid j \in J\right),\left(\max h_{i j \beta}^{\alpha} \mid j \in J^{\prime}\right), i=1,2, \ldots, n\right)$

In which, $\mathrm{J}=\{\mathrm{j}=1,2, \ldots \mathrm{m} \mid \mathrm{j}$ belongs to positive criteria $\}$ and $J^{\prime}=\{j=1,2, \ldots \mathrm{m} \mid \mathrm{j}$ belongs to negative criteria\}. The distance between positive ideal solution and negative ideal solution for each alternative is respectively calculated as follows:

$$
\begin{aligned}
& S_{i \beta}^{\alpha+}=\sqrt{\sum_{j=1}^{m}\left(h_{i j \beta}^{\alpha}-h_{j \beta}^{\alpha+}\right)^{2}} \quad \mathrm{i}=1,2, \ldots ., \mathrm{n} \\
& S_{i \beta}^{\alpha-}=\sqrt{\sum_{j=1}^{m}\left(h_{i j \beta}^{\alpha}-h_{j \beta}^{\alpha-}\right)^{2}} \quad \mathrm{i}=1,2, \ldots ., \mathrm{n}
\end{aligned}
$$


The $S_{i \beta}^{\alpha+}$ and $S_{i \beta}^{\alpha-}$ represent the distance between the crisp performance scores of an alternative with respect to all criteria, all the positive and negative ideal solutions respectively. The relative closeness to the ideal solution for each alternative can be formulated using closeness coefficient, CC, as follows [7]:

$$
C C_{i \beta}^{\alpha}=\frac{S_{i \beta}^{\alpha-}}{S_{i \beta}^{\alpha+}+S_{i \beta}^{\alpha-}} \mathrm{i}=1,2, \ldots \mathrm{n}
$$

The $C C_{i \beta}^{\alpha}$ indicates a final performance score containing the decision maker's $\alpha$ degree of confidence about their valuations and degree of optimism. The larger final performance score expresses the more prior alternative.

\section{Model Application and Results}

\section{Case Study Area and Data Descriptions}

Total provincial roads lengths in Bali are $883.07 \mathrm{~km}$ [8]. These roads are distributed in eight regencies and one city in Bali. This study uses the same data employed in a previous study by Sutika [1]. Sutika [1] used macro transportation system to construct the main and sub criteria in determining provincial road handling in Bali. The system consists of three sub-systems; sub-system of activities (land use), movements (traffic flows), and network. These three sub-systems are related to each other and controlled by institutional sub-system [2].
In the land use sub-system, land will have a portion for certain activities. Meanwhile, movements are caused by the process of fulfilling needs, which cannot be met only at one type of land. Trips from one area to another will require transportation facilities including both mode of transport and infrastructures. Both are required to support the trips and are part of the network sub-system. Network sub-system facilitates a way for traffic movements so that its performance will be appropriately measured by road surface conditions and road functions of the network itself. As the result, road surface conditions and road functions are used as the sub-criteria for the network sub-system.

With reference to the Bali Provincial Regulation No. 3 Year 2005 on Spatial Planning of Bali Province [9], land use in Bali Province is divided into two allotments; protected areas, and development area including office area, tourism, holy places, and mining. This division will be considered as a basis to form the sub-criteria of land use sub-system. For the institutional sub-system two approaches were considered to form its sub-criteria. They are topdown and bottom-up approaches. Top-down approach refers to the priority of local government policy on road handling while bottom-up approach provides significant space for community participations.

The data in Sutika [1] was collected through a questionnaire survey to obtain preferences amongst ten experts concerning Bali provincial road handling priority. Pairwise comparisons for each level considering

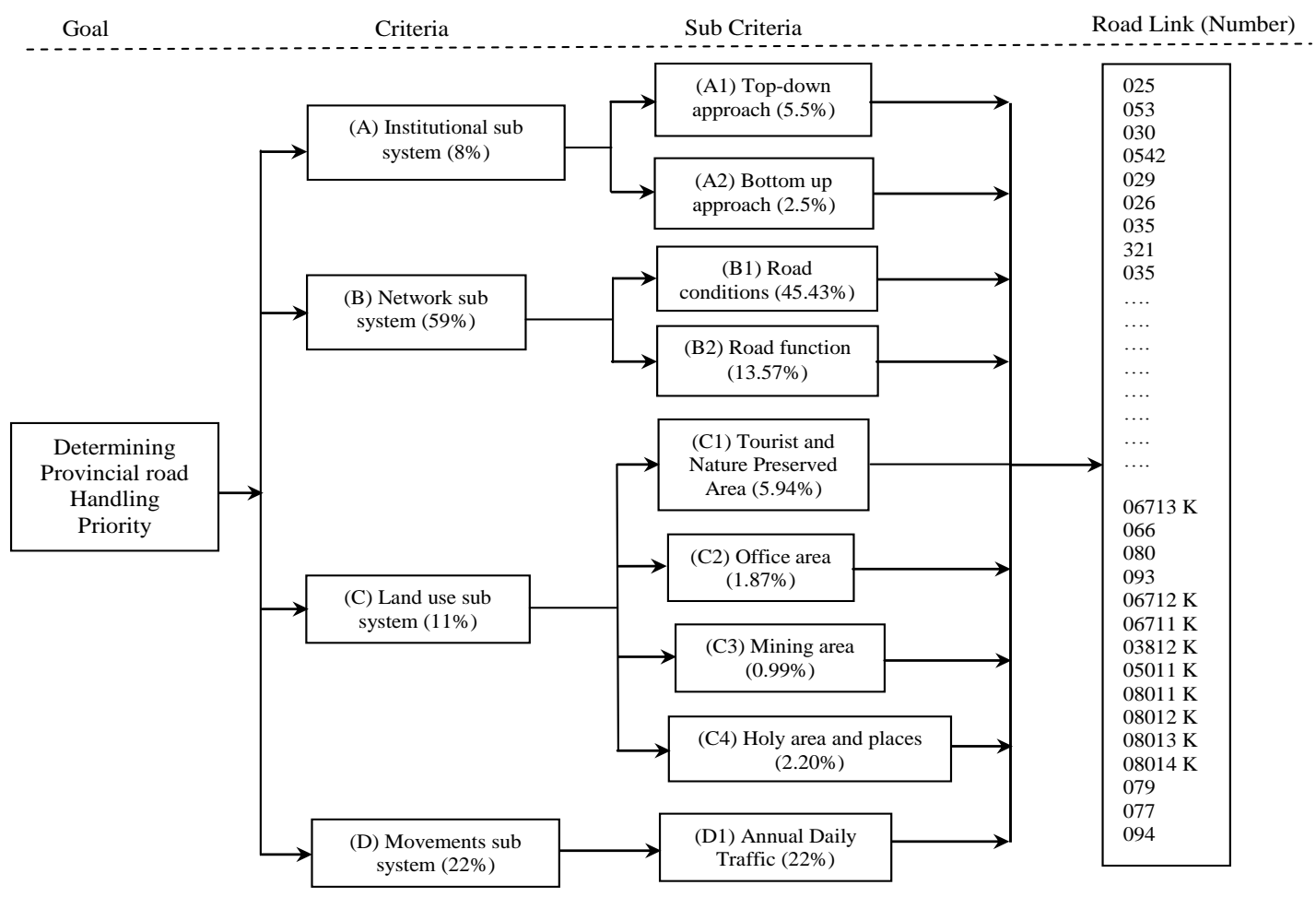

Figure 4. Hierarchy for Bali Provincial Road Handling Priority [1] 
goal of these experts were carried out using a ninepoint scale. Each pairwise comparison, PC was corresponded into an estimate of the priorities of the compared decision makers requirements [3].

The decision team making consisting ten experts of government officers, legislators, and academicians were involved in constructing these decision elements. The total number of alternatives considered in the study were a hundred and forty road links. These were all provincial road links in Bali. As the results, all weight vectors of main and sub criteria were presented in Figure 4 [1]. Due to space limitation, however, Figure 4 only shows some road link numbers.

Sutika [1] used the secondary data of the Department of Public Works of Bali Province which provides the scores of all sub criteria for each alternative road link. This includes the scores of a hundred and forty road links under different road surface conditions. The judgements therefore, were conducted for each alternative (road link). Once the overall weight coefficient for each alternative is obtained, the highest weight coefficient value is taken as the best alternative. A very high priority scale is used to determine the priority for all provincial (140) road links in Bali. This scale is determined using AHP 0.85 percentile score or greater. As the results, there were twenty one road links that fall into this category as shown in Table 2 [1]. In other words, out of a hundred and forty provincial road links in Bali, twenty one road links were found with a very high priority for road handling.

Table 2. Road Handling Priority using AHP 0.85 Percentile [1]

\begin{tabular}{|c|c|c|}
\hline $\begin{array}{l}\text { Road Link } \\
\text { Number }\end{array}$ & Road Link Descriptions & $\begin{array}{l}\text { No. Priority } \\
\text { using AHP }\end{array}$ \\
\hline 025 & JI Penelokan-Kubutambahan & 1 \\
\hline 053 & Л Rendang-Subagan & 2 \\
\hline 030 & Л Antosari-Pupuan & 3 \\
\hline 0542 & Л Petang-Kintamani & 4 \\
\hline 029 & Л Pupuan-Pekutatan & 5 \\
\hline 026 & Л Pupuan-Seririt & 6 \\
\hline 035 & J Klungkung-Besakih & 7 \\
\hline 069 & Л Jimbaran - Uluwatu & 8 \\
\hline 0553 & Л Kedewatan-Payangan-Batur Anyar & 9 \\
\hline 057 & Л Surabrata-Blatungan-Komuning & 10 \\
\hline 0551 & Л Tegaltamu-Kedewatan & 11 \\
\hline 064 & Л Wanagiri-Munduk-Mayong & 12 \\
\hline 060 & JI Ubud-Tegalalang-Bubung Bayung & 13 \\
\hline 081 & Л Petang-Batunye & 14 \\
\hline 073 & Л1 Selat-Pasar Agung & 15 \\
\hline 092 & Л Serangan-Tanjung-Benoa & 16 \\
\hline 072 & Л Paksebali-Selat & 17 \\
\hline 067 & Л1Tabanan-Buruan-Batukaru & 18 \\
\hline 093 & Л Pempatan-Ban & 19 \\
\hline 076 & Л Tista-Lempuyang & 20 \\
\hline 04311K & Л Sp.Niti Mandala-Sp.Imam Bonjol & 21 \\
\hline
\end{tabular}

\section{Analysis and Results}

An AHP's crisp PC matrix used in the previous study [1] is fuzzified using the TFN $\mathrm{f}=(\mathrm{l}, \mathrm{m}, \mathrm{u})$ as shown in Table 3. Both lower, $l$ and upper, $\mathrm{u}$, bounds present the uncertain range, that may occur within the expert's preferences. These TFNs are used to build the comparison matrices (both the main and sub criteria) of FAHP based on pairwise comparison technique.

Table 3. Conversion of Crisp PCM - Fuzzy PCM [10]

\begin{tabular}{|c|c|c|c|}
\hline $\begin{array}{l}\text { Crisp } \\
\text { PCM } \\
\text { value }\end{array}$ & $\begin{array}{l}\text { Fuzzy PCM } \\
\text { value }\end{array}$ & $\begin{array}{l}\text { Crisp } \\
\text { PCM } \\
\text { value }\end{array}$ & Fuzzy PCM value \\
\hline 1 & $\begin{array}{l}(1,1,1) \text { if diagonal } \\
(1,1,3) \text { otherwise }\end{array}$ & $1 / 1$ & $\begin{array}{l}(1 / 1,1 / 1,1 / 1) \text { if diagonal } \\
(1 / 3,1 / 1,1 / 1) \text { otherwise }\end{array}$ \\
\hline 2 & $(1,2,4)$ & $1 / 2$ & $(1 / 4,1 / 2,1 / 1)$ \\
\hline 3 & $(1,3,5)$ & $1 / 3$ & $(1 / 5,1 / 3,1 / 1)$ \\
\hline 5 & $(3,5,7)$ & $1 / 5$ & $(1 / 7,1 / 5,1 / 3)$ \\
\hline 7 & $(5,7,9)$ & $1 / 7$ & $(1 / 9,1 / 7,1 / 5)$ \\
\hline 9 & $(7,9,9)$ & $1 / 9$ & $(1 / 9,1 / 9,1 / 7)$ \\
\hline
\end{tabular}

A hierarchical structure for Bali provincial road handling priority problem is shown in Figure 4 . The ultimate goal is located at level 1 . At the next level, four major criteria are gathered so level 3 consisted of nine sub-criteria. Each road link is measured by all sub-criteria to obtain sub-scores. Each criterion respectively sums up its sub-scores. The sub scores of each road link with respect to all sub-criteria are obtained as shown in Table 4.

By Equation 4, all sub-scores of each road link are summed up with respect to the sub-criteria which belong to the same criterion to acquire all scores, $\tilde{G}_{i j}$. The scores of each road link with respect to institutional subsystem, A, are calculated as: $\tilde{G}_{11}=\tilde{G}_{111} \oplus \tilde{G}_{112} ; \tilde{G}_{11}=(7,9,9) \oplus(7,9,9)=(14,18,18)$ The rest may be calculated using the same way, so that the G matrix can be formed as shown in Table 5 .

Road conditions with respect to each road link is normalised following Equation 5 as follows:

$$
\begin{aligned}
\tilde{a}_{11} & =\frac{\tilde{G}_{11}}{\sqrt{\tilde{G}_{11}^{2} \oplus \tilde{G}_{21}^{2} \oplus \tilde{G}_{31}^{2}}}=\frac{(14,18,18)}{(35.043,44.000,53.329)} \\
& =(0.263,0.409,0.514)
\end{aligned}
$$

Using the same way, the fuzzy judgement matrix, A is constructed as shown in Table 6. A comprehensive pairwise comparison matrix, $\mathrm{D}$, is calculated by integrating the expert's different opinions using Equations 6 to 9. The D matrix is obtained as shown in Table 7. By using Equation 10, the fuzzy weight vector, $\mathrm{W}$, is obtained as shown in Table 8.

The fuzzy weight vector and the fuzzy judgement matrix are then combined to construct fuzzy performance matrix. Each criterion weight is multiplied with its corresponding criterion in the fuzzy judgement matrix to obtain the fuzzy performance matrix, H, as shown in Table 9. 
Table 4. Scores of Each Road Link

\begin{tabular}{lccccccccc}
\hline & A1 & A2 & B1 & B2 & C1 & C2 & C3 & C4 & D \\
\hline 025 & $\tilde{9}$ & $\tilde{9}$ & $\tilde{9}$ & $\tilde{9}$ & $\tilde{9}$ & $\tilde{1}$ & $\tilde{1}$ & $\tilde{9}$ & $\tilde{9}$ \\
053 & $\tilde{1}$ & $\tilde{9}$ & $\tilde{9}$ & $\tilde{9}$ & 9 & $\tilde{1}$ & $\tilde{1}$ & $\tilde{1}$ & $\tilde{9}$ \\
030 & $\tilde{9}$ & $\tilde{9}$ & $\tilde{9}$ & $\tilde{9}$ & $\tilde{1}$ & $\tilde{1}$ & $\tilde{1}$ & $\tilde{1}$ & $\tilde{9}$ \\
0542 & $\tilde{1}$ & $\tilde{9}$ & $\tilde{9}$ & $\tilde{9}$ & 9 & $\tilde{1}$ & $\tilde{1}$ & $\tilde{1}$ & $\tilde{9}$ \\
029 & $\tilde{9}$ & $\tilde{9}$ & $\tilde{9}$ & $\tilde{9}$ & $\tilde{1}$ & $\tilde{1}$ & $\tilde{1}$ & $\tilde{1}$ & $\tilde{9}$ \\
026 & $\tilde{9}$ & $\tilde{1}$ & $\tilde{9}$ & $\tilde{9}$ & $\tilde{1}$ & $\tilde{1}$ & $\tilde{1}$ & $\tilde{1}$ & $\tilde{9}$ \\
035 & $\tilde{1}$ & $\tilde{9}$ & $\tilde{9}$ & $\tilde{9}$ & $\tilde{1}$ & $\tilde{1}$ & $\tilde{9}$ & $\tilde{9}$ & $\tilde{9}$ \\
069 & $\tilde{1}$ & $\tilde{1}$ & $\tilde{9}$ & $\tilde{1}$ & $\tilde{9}$ & $\tilde{1}$ & $\tilde{9}$ & $\tilde{9}$ & $\tilde{7}$ \\
0553 & $\tilde{1}$ & $\tilde{9}$ & $\tilde{9}$ & $\tilde{1}$ & $\tilde{9}$ & $\tilde{1}$ & $\tilde{1}$ & $\tilde{1}$ & $\tilde{7}$ \\
057 & $\tilde{1}$ & $\tilde{1}$ & $\tilde{9}$ & $\tilde{9}$ & $\tilde{1}$ & $\tilde{1}$ & $\tilde{1}$ & $\tilde{1}$ & $\tilde{9}$ \\
0551 & $\tilde{1}$ & $\tilde{1}$ & $\tilde{9}$ & $\tilde{1}$ & $\tilde{9}$ & $\tilde{1}$ & $\tilde{1}$ & $\tilde{1}$ & $\tilde{7}$ \\
064 & $\tilde{1}$ & $\tilde{9}$ & $\tilde{9}$ & $\tilde{1}$ & $\tilde{9}$ & $\tilde{1}$ & $\tilde{1}$ & $\tilde{1}$ & $\tilde{9}$ \\
060 & $\tilde{1}$ & $\tilde{1}$ & $\tilde{9}$ & $\tilde{1}$ & $\tilde{9}$ & $\tilde{1}$ & $\tilde{1}$ & $\tilde{1}$ & $\tilde{7}$ \\
081 & $\tilde{1}$ & $\tilde{1}$ & $\tilde{9}$ & $\tilde{1}$ & $\tilde{1}$ & $\tilde{1}$ & $\tilde{1}$ & $\tilde{1}$ & $\tilde{7}$ \\
073 & $\tilde{1}$ & $\tilde{9}$ & $\tilde{9}$ & $\tilde{1}$ & $\tilde{1}$ & $\tilde{1}$ & $\tilde{9}$ & $\tilde{9}$ & $\tilde{9}$ \\
092 & $\tilde{1}$ & $\tilde{1}$ & $\tilde{9}$ & $\tilde{1}$ & $\tilde{1}$ & $\tilde{1}$ & $\tilde{1}$ & $\tilde{9}$ & $\tilde{9}$ \\
072 & $\tilde{1}$ & $\tilde{1}$ & $\tilde{9}$ & $\tilde{1}$ & $\tilde{1}$ & $\tilde{1}$ & $\tilde{9}$ & $\tilde{1}$ & $\tilde{9}$ \\
067 & $\tilde{1}$ & $\tilde{1}$ & $\tilde{9}$ & $\tilde{1}$ & $\tilde{1}$ & $\tilde{1}$ & $\tilde{1}$ & $\tilde{1}$ & $\tilde{9}$ \\
093 & $\tilde{1}$ & $\tilde{1}$ & $\tilde{9}$ & $\tilde{1}$ & $\tilde{1}$ & $\tilde{1}$ & $\tilde{9}$ & $\tilde{1}$ & $\tilde{9}$ \\
076 & $\tilde{1}$ & $\tilde{1}$ & $\tilde{9}$ & $\tilde{1}$ & $\tilde{1}$ & $\tilde{1}$ & $\tilde{1}$ & $\tilde{1}$ & $\tilde{9}$ \\
$04311 \mathrm{~K}$ & $\tilde{1}$ & $\tilde{1}$ & $\tilde{1}$ & $\tilde{9}$ & $\tilde{1}$ & $\tilde{1}$ & $\tilde{1}$ & $\tilde{1}$ & $\tilde{1}$ \\
\hline$W h$
\end{tabular}

\section{Where:}

A1 : Top down approach

B2 : Road function

C3 : Mining area

A2 : Bottom up approach

C1 : Tourist and Nature Preserved Area

C4 : Holly area and places

B1 : Road conditions

C2 : Office area

D : Annual Daily Traffic

Table 5. All Scores, G Matrix

\begin{tabular}{lcccc}
\hline \multicolumn{7}{c}{$\mathrm{A}$} & $\mathrm{B}$ & $\mathrm{C}$ & $\mathrm{D}$ \\
\hline 025 & $(14,18,18)$ & $(14,18,18)$ & $(16,20,24)$ & $(7,9,9)$ \\
053 & $(8,10,12)$ & $(14,18,18)$ & $(10,12,18)$ & $(7,9,9)$ \\
030 & $(14,18,18)$ & $(14,18,18)$ & $(4,4,12)$ & $(7,9,9)$ \\
0542 & $(8,10,12)$ & $(14,18,18)$ & $(10,12,18)$ & $(7,9,9)$ \\
029 & $(14,18,18)$ & $(14,18,18)$ & $(4,4,12)$ & $(7,9,9)$ \\
026 & $(8,10,12)$ & $(14,18,18)$ & $(4,4,12)$ & $(7,9,9)$ \\
035 & $(8,10,12)$ & $(14,18,18)$ & $(16,20,24)$ & $(7,9,9)$ \\
069 & $(2,2,6)$ & $(8,10,12)$ & $(22,28,30)$ & $(5,7,9)$ \\
0553 & $(8,10,12)$ & $(8,10,12)$ & $(10,12,18)$ & $(5,7,9)$ \\
057 & $(2,2,6)$ & $(14,18,18)$ & $(4,4,12)$ & $(7,9,9)$ \\
0551 & $(2,2,6)$ & $(8,10,12)$ & $(10,12,18)$ & $(5,7,9)$ \\
064 & $(8,10,12)$ & $(8,10,12)$ & $(10,12,18)$ & $(7,9,9)$ \\
060 & $(2,2,6)$ & $(8,10,12)$ & $(10,12,18)$ & $(5,7,9)$ \\
081 & $(2,2,6)$ & $(8,10,12)$ & $(4,4,12)$ & $(5,7,9)$ \\
073 & $(8,10,12)$ & $(8,10,12)$ & $(16,20,24)$ & $(7,9,9)$ \\
092 & $(2,2,6)$ & $(8,10,12)$ & $(10,12,18)$ & $(7,9,9)$ \\
072 & $(2,2,6)$ & $(8,10,12)$ & $(10,12,18)$ & $(7,9,9)$ \\
067 & $(2,2,6)$ & $(8,10,12)$ & $(4,4,12)$ & $(7,9,9)$ \\
093 & $(2,2,6)$ & $(8,10,12)$ & $(10,12,18)$ & $(7,9,9)$ \\
076 & $(2,2,6)$ & $(8,10,12)$ & $(4,4,12)$ & $(7,9,9)$ \\
$04311 \mathrm{~K}$ & $(2,2,6)$ & $(8,10,12)$ & $(4,4,12)$ & $(1,1,3)$ \\
\hline
\end{tabular}

Where:

A = Institutional sub-system $\quad B=$ Network sub-system

$\mathrm{C}=$ Land Use sub-system $\quad \mathrm{D}=$ Movements sub-system
During the priority ranking process, some unobvious factors which usually are ignored may deeply affect the decision results. Therefore, the experts' degree of confidence and degree of optimism should be brought up during defuzzification process so that approaching the real decision. The value of $\alpha$ indicates the experts' degree of confidence in their subjective evaluations concerning alternatives scores and criteria weight. The higher $\alpha$ value expresses the higher degree of confidence and closer to the possible value of the triangular fuzzy numbers. In addition, by using the $\beta$ value (optimism index), defuzzification is conducted to obtain the crisp performance scores.

The crips performance scores and TOPSIS methods (Equations 14 to 18) are employed to determine the road link priority. The results which also showing the sensitivity analyses are depicted in Figures 5 to 7. These graphs show $\beta$ value as $0.05,0.5$ and 0.95 reflecting the pessimistic, the moderate, and the optimistics situations respectively. The horizontal and vertical axes showing the $\alpha$ varying from 0 to 1 and the closeness coefficient, $\mathrm{CC}$ values respectively.

The CC indicates the distance of road links from positive ideal solution in which the higher $\mathrm{CC}$ value expressing the higher priority. From the graphs, mutual comparisons can be performed from the most uncertain situation $(\alpha=0)$ to the most certain situation $(\alpha=1)$, from which the relative Bali provincial road link handling priority can be realised. Based on Figures 5 and 6, the Jl. PenelokanKubutambahan (025) is a road link with the highest priority in both pessimistic $(\beta=0.05)$ and moderate situations $(\beta=0.50)$ and from about certain $(\alpha<0.5)$ to the most uncertain conditions $(\alpha<0.35)$. Meanwhile, Jl. Selat-Pasar Agung (073) is a road link with highest priority in such both situations and from about certain to the most certain conditions.

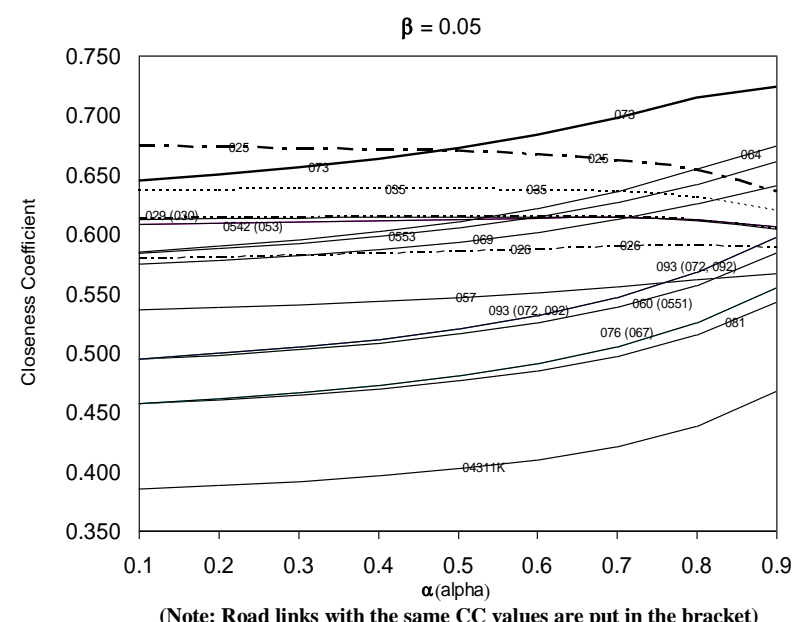

Figure 5. Sensitivity Analysis-Pessimistic Situation 
Table 6. Fuzzy Judgement Matrix

\begin{tabular}{lcccc}
\hline \multicolumn{7}{c}{$\mathrm{A}$} & $\mathrm{B}$ & $\mathrm{C}$ & $\mathrm{D}$ \\
\hline 025 & $(0.263,0.409,0.514)$ & $(0.189,0.266,0.337)$ & $(0.158,0.265,0.391)$ & $(0.155,0.217,0.287)$ \\
053 & $(0.150,0.227,0.342)$ & $(0.189,0.266,0.337)$ & $(0.099,0.159,0.294)$ & $(0.155,0.217,0.287)$ \\
030 & $(0.263,0.409,0.514)$ & $(0.189,0.266,0.337)$ & $(0.040,0.053,0.196)$ & $(0.155,0.217,0.287)$ \\
0542 & $(0.150,0.227,0.342)$ & $(0.189,0.266,0.337)$ & $(0.099,0.159,0.294)$ & $(0.155,0.217,0.287)$ \\
029 & $(0.263,0.409,0.514)$ & $(0.189,0.266,0.337)$ & $(0.040,0.053,0.196)$ & $(0.155,0.217,0.287)$ \\
026 & $(0.150,0.227,0.342)$ & $(0.189,0.266,0.337)$ & $(0.040,0.053,0.196)$ & $(0.155,0.217,0.287)$ \\
035 & $(0.150,0.227,0.342)$ & $(0.189,0.266,0.337$ & $(0.158,0.265,0.391)$ & $(0.155,0.217,0.287)$ \\
069 & $(0.038,0.045,0.171)$ & $(0.108,0.148,0.225)$ & $(0.218,0.371,0.489)$ & $(0.111,0.169,0.287)$ \\
0553 & $(0.150,0.227,0.342)$ & $(0.108,0.148,0.225)$ & $(0.099,0.159,0.294)$ & $(0.111,0.169,0.287)$ \\
057 & $(0.038,0.045,0.171)$ & $(0.189,0.266,0.337)$ & $(0.040,0.053,0.196)$ & $(0.155,0.217,0.287)$ \\
0551 & $(0.038,0.045,0.171)$ & $(0.108,0.148,0.225)$ & $(0.099,0.159,0.294)$ & $(0.111,0.169,0.287)$ \\
064 & $(0.150,0.227,0.342)$ & $(0.108,0.148,0.225)$ & $(0.099,0.159,0.294)$ & $(0.155,0.217,0.287)$ \\
060 & $(0.038,0.045,0.171)$ & $(0.108,0.148,0.225)$ & $(0.099,0.159,0.294)$ & $(0.111,0.169,0.287)$ \\
081 & $(0.038,0.045,0.171)$ & $(0.108,0.148,0.225)$ & $(0.040,0.053,0.196)$ & $(0.111,0.169,0.287)$ \\
073 & $(0.150,0.227,0.342)$ & $(0.108,0.148,0.225)$ & $(0.158,0.265,0.391)$ & $(0.155,0.217,0.287)$ \\
092 & $(0.038,0.045,0.171)$ & $(0.108,0.148,0.225)$ & $(0.099,0.159,0.294)$ & $(0.155,0.217,0.287)$ \\
072 & $(0.038,0.045,0.171)$ & $(0.108,0.148,0.225)$ & $(0.099,0.159,0.294)$ & $(0.155,0.217,0.287)$ \\
067 & $(0.038,0.045,0.171)$ & $(0.108,0.148,0.225)$ & $(0.040,0.053,0.196)$ & $(0.155,0.217,0.287)$ \\
093 & $(0.038,0.045,0.171)$ & $(0.108,0.148,0.225)$ & $(0.099,0.159,0.294)$ & $(0.155,0.217,0.287)$ \\
076 & $(0.038,0.045,0.171)$ & $(0.108,0.148,0.225)$ & $(0.040,0.053,0.196)$ & $(0.155,0.217,0.287)$ \\
$04311 \mathrm{~K}$ & $(0.038,0.045,0.171)$ & $(0.108,0.148,0.225)$ & $(0.040,0.053,0.196)$ & $(0.022,0.024,0.096)$ \\
\hline Where: & & & & \\
A = Institutional sub-system $\quad \mathrm{B}=$ Network sub-system $\quad \mathrm{C}=$ Land Use sub-system & $\mathrm{D}=$ Movements sub-system
\end{tabular}

Table 7. Pairwise Comparison Matrix

\begin{tabular}{|c|c|c|c|c|}
\hline & $\mathrm{A}$ & $\mathrm{B}$ & $\mathrm{C}$ & $\mathrm{D}$ \\
\hline $\mathrm{A}$ & $(1.000,1.000,1.000)$ & $(0.111,0.513,3.000)$ & $(0.200,0.840,3.000)$ & $(0.200,0.613,3.000)$ \\
\hline B & $(0.333,6.133,9.000)$ & $(1.000,1.000,1.000)$ & $(1.000,4.800,7.000)$ & $(1.000,4.400,7.000)$ \\
\hline $\mathrm{C}$ & $(0.333,2.333,5.000)$ & $(0.143,0.282,1.000)$ & $(1.000,1.000,1.000)$ & $(0.200,0.507,1.000)$ \\
\hline $\mathrm{D}$ & $(0.333,3.333,5.000)$ & $(0.143,0.362,1.000)$ & $(1.000,2.800,5.000)$ & $(1.000,1.000,1.000)$ \\
\hline
\end{tabular}

Table 8. Fuzzy Weight Vector

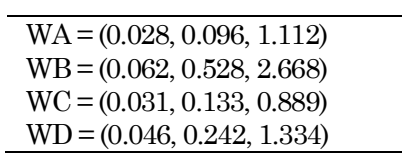

Table 9. Fuzzy Performance Matrix

\begin{tabular}{lcccc}
\hline & $\mathrm{A}$ & $\mathrm{B}$ & $\mathrm{C}$ & $\mathrm{D}$ \\
\hline 025 & $(0.007,0.039,0.571)$ & $(0.012,0.140,0.900)$ & $(0.005,0.035,0.348)$ & $(0.007,0.053,0.383)$ \\
053 & $(0.004,0.022,0.381)$ & $(0.012,0.140,0.900)$ & $(0.003,0.021,0.261)$ & $(0.007,0.053,0.383)$ \\
030 & $(0.007,0.039,0.571)$ & $(0.012,0.140,0.900)$ & $(0.001,0.007,0.174)$ & $(0.007,0.053,0.383)$ \\
0542 & $(0.004,0.022,0.381)$ & $(0.012,0.140,0.900)$ & $(0.003,0.021,0.261)$ & $(0.007,0.053,0.383)$ \\
029 & $(0.007,0.039,0.571)$ & $(0.012,0.140,0.900)$ & $(0.001,0.007,0.174)$ & $(0.007,0.053,0.383)$ \\
026 & $(0.004,0.022,0.381)$ & $(0.012,0.140,0.900)$ & $(0.001,0.007,0.174)$ & $(0.007,0.053,0.383)$ \\
035 & $(0.004,0.022,0.381)$ & $(0.012,0.140,0.900)$ & $(0.005,0.035,0.348)$ & $(0.007,0.053,0.383)$ \\
069 & $(0.001,0.004,0.190)$ & $(0.007,0.078,0.600)$ & $(0.007,0.049,0.435)$ & $(0.005,0.041,0.383)$ \\
0553 & $(0.004,0.022,0.381)$ & $(0.007,0.078,0.600)$ & $(0.003,0.021,0.261)$ & $(0.005,0.041,0.383)$ \\
057 & $(0.001,0.004,0.190)$ & $(0.012,0.140,0.900)$ & $(0.001,0.007,0.174)$ & $(0.007,0.053,0.383)$ \\
0551 & $(0.001,0.004,0.190)$ & $(0.007,0.078,0.600)$ & $(0.003,0.021,0.261)$ & $(0.005,0.041,0.383)$ \\
064 & $(0.004,0.022,0.381)$ & $(0.007,0.078,0.600)$ & $(0.003,0.021,0.261)$ & $(0.007,0.053,0.383)$ \\
060 & $(0.001,0.004,0.190)$ & $(0.007,0.078,0.600)$ & $(0.003,0.021,0.261)$ & $(0.005,0.041,0.383)$ \\
081 & $(0.001,0.004,0.190)$ & $(0.007,0.078,0.600)$ & $(0.001,0.007,0.174)$ & $(0.005,0.041,0.383)$ \\
073 & $(0.004,0.022,0.381)$ & $(0.007,0.078,0.600)$ & $(0.005,0.035,0.348)$ & $(0.007,0.053,0.383)$ \\
092 & $(0.001,0.004,0.190)$ & $(0.007,0.078,0.600)$ & $(0.003,0.021,0.261)$ & $(0.007,0.053,0.383)$ \\
072 & $(0.001,0.004,0.190)$ & $(0.007,0.078,0.600)$ & $(0.003,0.021,0.261)$ & $(0.007,0.053,0.383)$ \\
067 & $(0.001,0.004,0.190)$ & $(0.007,0.078,0.600)$ & $(0.001,0.007,0.174)$ & $(0.007,0.053,0.383)$ \\
093 & $(0.001,0.004,0.190)$ & $(0.007,0.078,0.600)$ & $(0.003,0.021,0.261)$ & $(0.007,0.053,0.383)$ \\
076 & $(0.001,0.004,0.190)$ & $(0.007,0.078,0.600)$ & $(0.001,0.007,0.174)$ & $(0.007,0.053,0.383)$ \\
$04311 \mathrm{~K}$ & $(0.001,0.004,0.190)$ & $(0.007,0.078,0.600)$ & $(0.001,0.007,0.174)$ & $(0.001,0.006,0.128)$ \\
\hline
\end{tabular}

Where:

A= Institutional sub-system $\quad B=$ Network sub-system $\quad C=$ Land Use sub-system $\quad D=$ Movements sub-system 


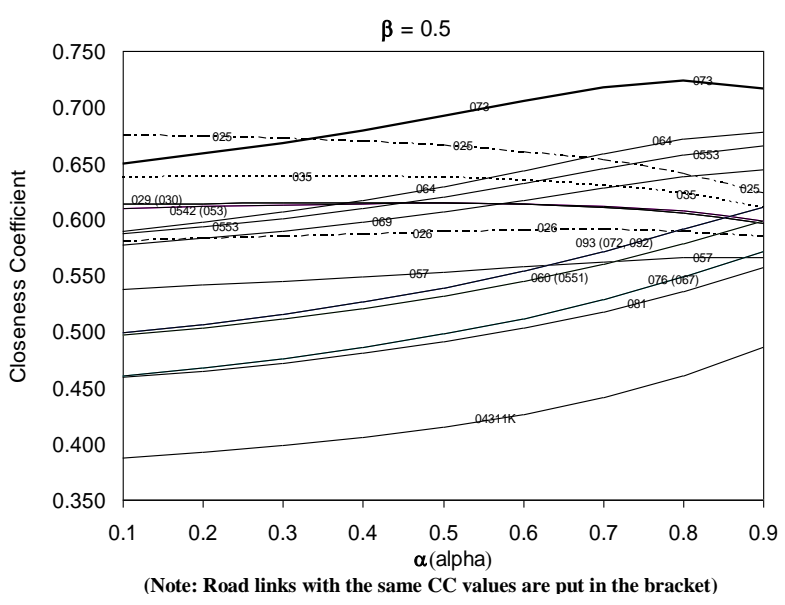

Figure 6. Sensitivity Analysis - Moderate Situation

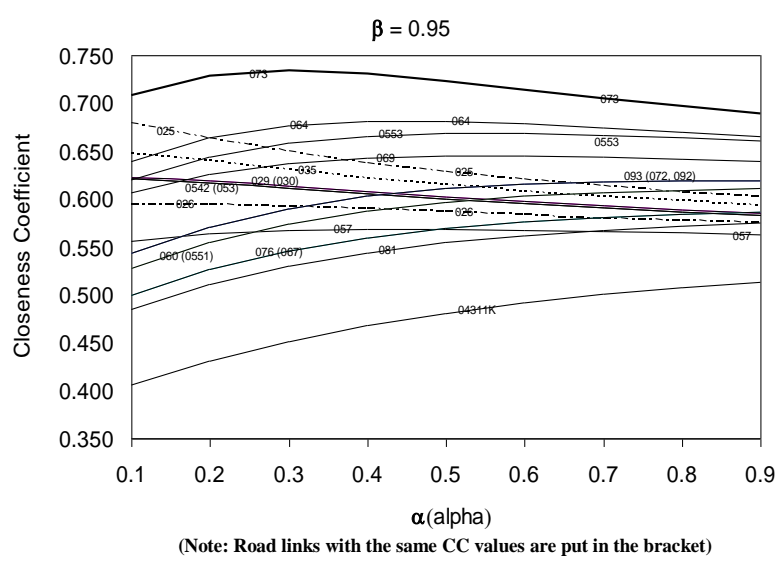

Figure 7. Sensitivity Analysis-Highly Optimistic Situation

Figure 7 shows that Л. Selat-Pasar Agung (073) is a road link with the highest priority in higly optimistic situation $(\beta=0.95)$ and for all conditions. For pessimistic, moderate and optimistic situations and for all conditions ranging from under the most uncertain to certain comparisons, a road link connecting between Лl Sp.Niti Mandala-Sp.Imam Bonjol (04311K) has the lowest priority.

Apparently, Figures 5, 6, and 7 show 15 priority lines instead of 21 lines. This is because some road links have the same CC values. These similar road links numbers are put in the bracket.

Meanwhile, the ranking of road handling priority in the previous study using the AHP method for the same set of data is shown in Table 2 [1]. The table shows that Jl Penelokan-Kubutambahan (025) is a road link with the highest road handling priority. The current study results shows that Jl. PenelokanKubutambahan (025) is a road link with the highest priority in both pessimistic $(\beta=0.05)$ and moderate situations $(\beta=0.50)$ and from about certain $(\alpha<0.5)$ to the most uncertain conditions $(\alpha<0.35)$. This is shown in Figures 5 and 6. Meanwhile, both previous and current studies suggest that Jl Sp.Niti MandalaSp.Imam Bonjol (04311K) has the lowest road handling priority.

The rest of the priority resulted from the current study, however is different to the previous study. The road handling priority resulted from this study however, is preferred in comparison to that of the previous study as the current study has also considered the decision maker's degrees of confidence and optimism of the decision.

\section{Conclusions}

In this study, Fuzzy AHP $\alpha$-cut based and TOPSIS methods are employed to determine Bali provincial road handling priority. A very high priority scale is used to determine the priority for all provincial (140) road links in Bali. This scale is determined using AHP 0.85 percentile score or greater. As the results, there are twenty one road links that fall into this category. These road links are analysed using FAHP $\alpha$-cut based and TOPSIS methods to determine Bali provincial road handling priority.

The decision maker's degree of optimism in Bali Province, however, may have considerable impact on decision making. Adoption of these FAHP $\alpha$-cut based and TOPSIS methods allow the researcher to estimate the overall road handling priority from optimistic to pessimistic and from under the most uncertain to certain comparisons.

The previous study results using the AHP method are compared to the current study for the same set of data. The current study shows that decision makers' degree of confidence in both pessimistic and moderate situations and optimism from about certain to the most uncertain conditions suggesting the same road link as the highest priority compared to the previous study. Both current and previous studies also conclude the same road link as the lowest road handling priority. The road handling priority resulted from this study, however, is preferred in comparison to that of the previous study as the current study has also considered the decision maker's degrees of confidence and optimism of decision.

\section{References}

1. Sutika, I.K., Determining Provincial Road Handling Priority in Badung Regency using AHP Method (in Indonesian), M.Eng Thesis, Postgraduate Programme in Civil Engineering, Udayana University, Bali, 2010.

2. Tamin, O.Z., Transport Modelling and Planning (in Indonesian). Bandung: ITB Press, 1997. 
3. Kwong, C.K. and Bai, H., A Fuzzy AHP Approach to the Determination of Importance Weights of Customer Requirements in Quality Function Deployment, Journal of Intelligent Manufacturing, Vol. 13, 2002, pp. 367-377.

4. Saaty, T.L., Decision Making for Leaders: The Analytical Hierarchy Process for Decision in Complex World. Pittsburgh: University of Pittsburgh, 1986.

5. Vahidnia, M.H., Alesheikh, A., Alimohammadi, A., and Bassiri, A., Fuzzy Analytical Hierarchy Process in GIS Application, The International Archives of the Photogrammetry, Remote Sensing and Spatial Information Sciences, Vol. XXXVII, Part B2, Beijing, 2008.

6. Dagdeviren, M., Yavuz, S., and Kllınç, N., Weapon selection using the AHP and TOPSIS Methods under Fuzzy Environment, Expert Systems with Applications, Vol. 36, 2009, pp. 8143-8151.

7. Ball, S. and Korukoğlu, S., Operating System Selection Using Fuzzy AHP and TOPSIS Methods, Mathematical and Computational Applications, Vol. 14, No.2, 2009, pp. 119-130.

8. Department of Public Works, 2009-2013 Strategic Planning. Department of Public Works of Province of Bali (in Indonesian), Bali, 2009.

9. Bali Provincial Government, Bali Provincial Regulation No. 3 2005: Spatial Planning of Bali Province 2005-2010 (in Indonesian), Bali, 2005.

10. Prakash, T.N., Land Suitability Analysis for Agricultural Crops: A Fuzzy Multicriteria Decision Making Approach, MSc Thesis, International Institute for Geo-Information Science and Earth Observation, The Netherlands, 2003. 